\title{
Depressed mood in a cohort of elderly medical inpatients: Prevalence, clinical correlates and recognition rate ${ }^{1}$
}

\author{
R. Pouget ${ }^{1}$, B. Yersin ${ }^{2}$, V. Wietlisbach ${ }^{3}$, B. Burnand ${ }^{3}$, and C.J. Büla ${ }^{1,2}$ \\ ${ }^{1}$ Division of Geriatric Medicine, and ${ }^{2}$ Department of Internal Medicine, Centre Hospitalier Universitaire \\ Vaudois (CHUV), Lausanne, ${ }^{3}$ Institute of Social and Preventive Medicine, University of Lausanne, Lausanne, \\ Switzerland
}

ABSTRACT. The objectives of this prospective cohort study were to 1) determine the prevalence of depressed mood, 2) identify the characteristics associated with it, and 3) evaluate the recognition rate of depressed mood by clinicians. The study population was a cohort of 401 elderly patients, aged 75 years and older, admitted to the internal medicine service of a tertiary care academic medical center in Western Switzerland over six months. We excluded patients with severe cognitive impairment, terminal disease or those living in a nursing home. Data on demographics, medical, physical, social and mental status were collected upon admission. Presence of depressed mood was defined as a score $\geq 6$ on the Geriatric Depression Scale (GDS), short form (15-item). An independent reviewer performed a discharge summary abstraction to assess recognition rate. Subjects mean age was 82.4 years, $60.9 \%$ were women. Overall, 90 patients (22.4\%) had an abnormal GDS score ( $\geq 6)$. Compared to those without a depressed mood, these subjects were (all $\mathrm{p}<0.05$ ) older $(83.5$ vs 82.0 years), more frequently living alone (66.7 vs $55.0 \%)$, dependent in both basic activities of daily living (BADL) and instrumental ADL (48.9 vs $36.0 \%$, and 91.1 vs $84.9 \%$, respectively), and cognitively impaired (47.8 vs $27.7 \%$ with MMSE score $<24)$. In addition, they had more comorbidities (Charlson index 1.6 vs 1.2). In multivariate analysis, an independent association remains for subjects living alone (OR 1.8, 95\%CI 1.1-3.0), with cognitive impairment (OR 1.9, 95\%CI 1.1-3.2), and comorbidities (OR 1.3 per point, 95\% CI 1.11.5). Detection rate during the index hospitaliza- tion was only $16.7 \%$ (15/90). In conclusion, depressed mood was frequent but rarely detected in this population. These findings emphasize the need to improve screening efforts, and to develop additional strategies such as using a pre-screening question to enhance clinical recognition.

(Aging Clin. Exp. Res. 12: 301-307, 2000)

${ }^{\circ} 2000$, Editrice Kurtis

\section{INTRODUCTION}

Depression is the most frequently occurring psychiatric problem in elderly persons, and hospitalized elderly particularly seem at increased risk (1-6). Interaction between depression and physical illness is complex. Several prospective studies of elderly persons in community and institutional settings, including general medical inpatients as well as patients suffering from specific conditions such as acute myocardial infarction, have shown independent associations between depression and mortality (7-15). For example, in this latter study of patients hospitalized with myocardial infarction, those with major depression were more than three times as likely to die over a 6-month follow-up period than those without depression (15). Of note, the reduced survival time of depressed patients observed in these studies was not explained by greater disease severity or greater levels of comorbid illness (7-15). Depression has also been consistently associated with an increased risk of functional status decline (3, 16-19). Indeed, a recent systematic review of risk factors for functional decline in elderly persons revealed that depression is one of the factors whose link to functional decline had the

\footnotetext{
${ }^{1}$ This paper was presented, in part, at the Gerontological Society of America Annual Meeting, San Francisco, CA, 1999.

Key words: Depressed mood, depression, hospitalized elderly, screening for depression.

Correspondence: C.J. Büla, M.D., CUTR Sylvana, Ch. de Sylvana 10, 1066 Epalinges, Switzerland.

E-mail: Christophe.Bula@chuv.hospvd.ch

Received January 5, 2000; accepted in revised form May 8, 2000.
} 
highest strength of evidence (16). As a consequence, depression has also been associated with increased health services utilization, and cost (20-22).

Despite these observations and evidence of treatment efficacy $(23,24)$, studies in different settings have shown that depressive problems remain undetected and untreated in 50 to $90 \%$ of elderly inpatients $(3,25-27)$. To enhance detection, one strategy has been to identify patient characteristics associated with the presence of depressive problems $(2,7,27$ 32). However, these studies were limited to small or selected populations, or lacked adequate adjustment for co-morbidities in multivariate models. While functional impairment, lack of social support, and severity of medical illnesses have been identified as risk factors in most studies, the significance of age, gender, race or cognitive impairment remains controversial (7, 27-32). In addition, these studies took place almost wholly in the US and British health care environment, and primarily in nursing homes and community settings. Finally, studies have differed in the method of assessment and criteria used to define depression.

We decided to examine the issues of depressed mood prevalence, risk factors, and detection in our acute health care environment. We used data from a cohort of elderly hospitalized patients enrolled in a larger study on functional assessment in the acute care setting. The objectives of this study were to 1 ) determine the prevalence of depressed mood in a cohort of elderly medical inpatients, 2) identify clinical characteristics associated with the presence of depressed mood, and 3) evaluate the detection rate of depressed mood by hospital physicians.

\section{SUBJECTS AND METHODS}

\section{Study population and setting}

Potential participants were alternate patients aged 75 years and over admitted to the internal medicine service of an academic medical center located in Western, French-speaking Switzerland, over a 6-month period. From the original 649 patients, 135 (20.8\%) were not included because they stayed less than 48 hours in the hospital $(\mathrm{N}=10)$, were already living in a nursing home $(\mathrm{N}=43)$, were transferred from a regional or out of state hospital for an elective procedure $(\mathrm{N}=32)$, or had private insurance $(\mathrm{N}=50)$. These latter patients were not included because of the inability to access the administrative and followup data needed for the larger study.

In addition, 106 (16.3\%) were excluded because of their inability to answer questions due to severe cognitive impairment (defined as the inability to give his/her name and date of birth, $\mathrm{N}=29$ ), aphasia or stroke $(\mathrm{N}=9)$, unstable medical conditions, including patients admitted to intensive care units $(\mathrm{N}=20)$, terminal illness or coma $(\mathrm{N}=23)$, or other reasons (e.g., language barrier) $(\mathrm{N}=25)$. In addition, 7 patients $(1.1 \%)$ refused to participate in the study. Thus, a total of 401 patients were eventually recruited. Excluded patients had a similar age and gender distribution but, as expected, died more frequently during their hospital stay $(25.0 \%$ vs $5.0 \%, p<0.005)$. The study was approved by the institutional review board of the Faculty of Medicine, University of Lausanne, Switzerland. Written informed consent for participation was obtained from each patient.

\section{Data collection}

Within 48 hours of admission, a trained research nurse interviewed the patients at bedside. Data were collected using a structured instrument, and included demographics, living situation, educational level, selfrated income, informal help, mobility, as well as basic activities of daily living (BADL) (33) and instrumental activities of daily living (IADL) (34). For ADL measures, a patient was considered dependent in an activity if unable to perform the task without assistance. Selfperceived health status, cognitive status [Folstein's Mini Mental State Exam (MMSE), (35)] and affective status [Yesavage's Geriatric Depression Scale, short form (GDS), (36)] were also assessed. Because the GDS focuses on the non-somatic symptoms of depression, this scale appears especially appropriate in populations of acutely ill elderly patients. The short form used in this study was derived from a previously validated French version (37). Weekly meetings were used to review functional status data quality. Home care services were systematically contacted to collect data on formal help received at home prior to hospitalization. In addition, in-hospital BADL performance was obtained from the ward nurse in charge of the patient. Main admission diagnosis, Charlson comorbidity index (38) and data on medication prescribed at home were collected from the medical records. Information about length of stay and destination after discharge were collected from the administrative files.

\section{Assessment and recognition of depressed mood}

To define depressed mood, we used the commonly recommended GDS cut-off of 6 or more depressive symptoms, which has been shown in previous studies to have a sensitivity ranging from 85 to $88 \%$, with specificity of 62 to $71 \%(35,39,40)$. Although a score of 6 is not equivalent to major depression, it implies a depressive symptomatology 
significant enough to justify further evaluation for depression.

To assess the recognition of depressed mood, a separate reviewer, blinded to the GDS results, performed a discharge summary review. Depressed mood was considered recognized if either mentioned in the discharge diagnoses, in the discussion section of the discharge summary, or if an antidepressant was prescribed at discharge. Low dose amitryptiline prescribed for painful chronic neuropathy (e.g., diabetic, post-zoster) was not considered as an antidepressant treatment unless specified in other parts of the discharge summary. To maximize sensitivity of our definition of a recognized case, we also included subjects with a prescription for daytime benzodiazepines at discharge (i.e., not prescribed only as a sleeping pill). Although benzodiazepines are not considered an appropriate treatment for depression, they are sometimes prescribed for this condition (41). Reliability of recognition assessment was tested in a random sample of 50 discharge summaries abstract- ed by a second reviewer, blinded to the first reviewer's and GDS's results. Inter-rater agreement was 94\% (kappa $=0.74, p<0.001$ ).

\section{Statistical analysis}

The characteristics of subjects with and without depressed mood were first compared in bivariate analysis using $\chi^{2}$ or Fischer's exact tests, depending on the distribution, for categorical variables. Student's $t$-test was used for continuous variables. A stepwise multivariate logistic regression analysis was performed to identify baseline characteristics independently associated with the presence of depressed mood. To be included in the multivariate model, variables had to show a statistically significant association in bivariate analysis. Because some variables were highly correlated (e.g., pre-admission BADL and IADL, admission BADL, and MMSE), we decided a priori to preferentially include in the initial model variables that resulted from objective rather than self-report measures (e.g., nurse-observed

Table 1 - Baseline characteristics of the total population and bivariate comparisons in patients with and without a depressed mood (defined as a GDS score $\geq 6$ ).

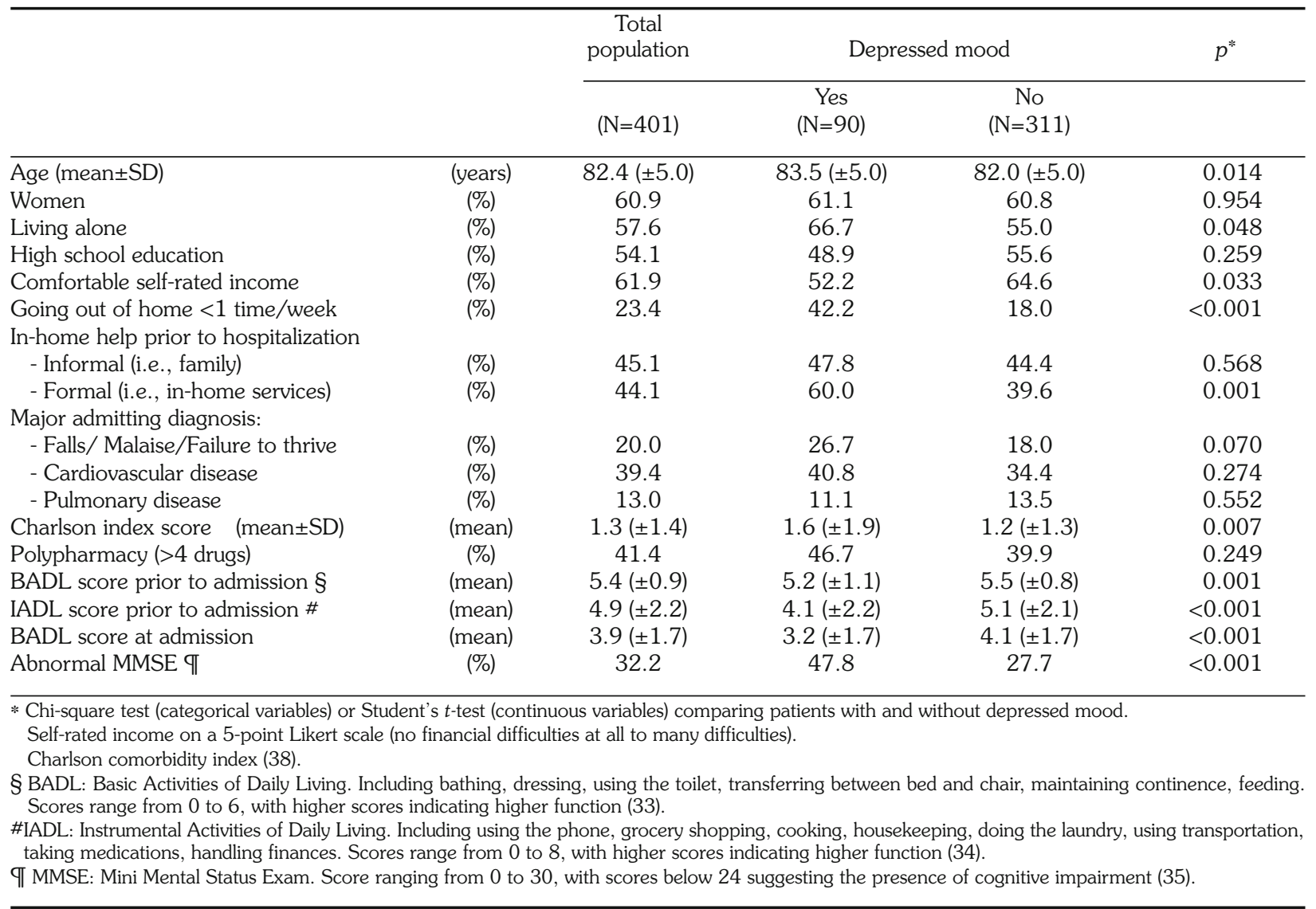


BADL performance at admission rather than self-reported BADL prior to hospitalization). The significance levels to enter and to remain in the model were set at 0.2 and 0.3, respectively. Statistical analyses were performed using Stata 6.0 (Stata Corp, College Station, TX).

\section{RESULTS}

Baseline characteristics of the entire study population are shown in the first column of Table 1 . The typical subject was an 82.4 years old woman, living alone, with a high school education, who rated her income as comfortable. The most frequent admitting diagnoses were cardiovascular disorders (39.4\%), while falls, malaise, and failure to thrive accounted for $20.0 \%$ of the admissions. At the time of admission, more than two thirds had at least one comorbidity, and about $13 \%$ had three or more (Charlson index). Self-perceived health was rated fair or poor by $52.1 \%$ of patients. While the mean number of prescription drugs was 4.5 (range 0 to 20), $5 \%$ of the patients were not taking any medication. Dependency in one or more BADL and IADL was reported by $38.9 \%$ and $86.3 \%$ of the population, respectively. Abnormal GDS $(\geq 6)$ and MMSE $(<24)$ scores were observed in $22.4 \%$ and $32.2 \%$ of the patients, respectively. Distribution of the GDS score in the study population is shown in Figure 1.

The median length of stay was 8.0 days (mean: 10.3 , range: $1-100)$. Overall, 20 patients $(5.0 \%)$ died during their hospital stay.

In bivariate analysis (Table 1), patients with a depressed mood were older and more frequently living alone. They infrequently left their home, and received

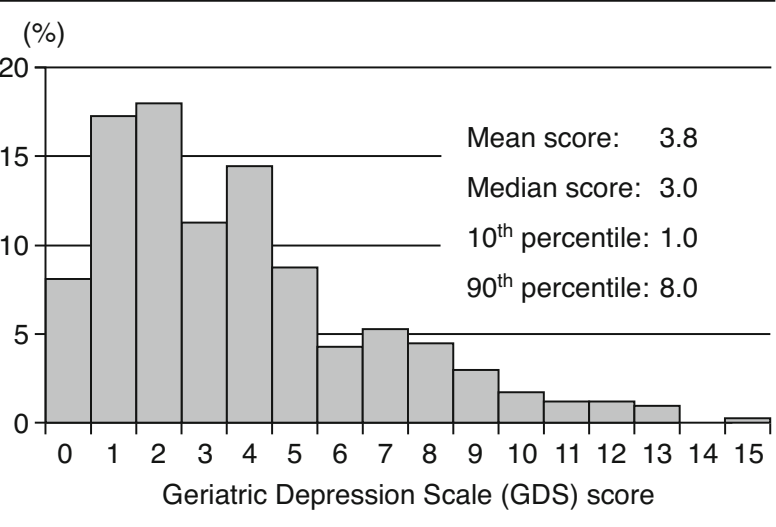

Figure 1 - Distribution of Geriatric Depression Scale (GDS) scores in the study population. formal help by in-home care services more often. Admitting diagnoses of falls, malaise and failure to thrive tended to be more frequent in patients with depressed mood. In addition, the amount of comorbidity was higher for patients with depressed mood, who were also more impaired in basic and instrumental ADL before hospitalization, and in basic ADL at admission. In addition, they more frequently had an abnormal MMSE score $(<24)$.

In multivariate analysis (Table 2), an independent association with the presence of a depressed mood remained for patients living alone, and those with an abnormal MMSE score. These patients were 1.8 times and 1.9 times, respectively, more likely to have depressed mood. The likelihood of having a depressed mood also increased with an increase in comorbidity using the Charlson index. Several variables that were significantly associated with the presence of depressed mood in bivariate analysis, such as preadmission functional status and mobility, did not remain in the model after controlling for admission BADL and MMSE status. Similarly, formal help received prior to hospital admission did not remain in the model after controlling for the living situation (living alone). Overall, the model performed better than chance in discriminating patients with and without depression (area under the ROC curve of 0.68), but its clinical usefulness is obviously limited by the amount and type of data required (e.g., MMSE, Charlson index), when compared to GDS administration. Moreover, based on this model, we attempted to stratify the population according to the presence of 0,1 , and 2 or 3 risk factors for depression (i.e., living alone, having an abnormal MMSE, and having one or more comorbidities). The resulting groups had only $9.2 \%, 19.3 \%$ and $32.9 \%$ of the subjects with depressed mood. Thus, even in the highest risk group defined by this model, two thirds of the subjects did not report depressed mood by GDS.

Results of sensitivity analyses using higher GDS cut-off scores to define depressed mood are shown in Table 2. Results were not substantially modified except for the living situation variable (living alone), which did not remain in the model when using a GDS cut-off of 10 or more as the dependent variable. This is likely due to the too small number $(\mathrm{N}=22)$ of subjects with an abnormal GDS in this subgroup analysis.

In addition, because severe cognitive impairment has been shown to alter psychometric properties of the GDS, we repeated the analysis after excluding 30 subjects with MMSE scores lower than 16. Results were unchanged (Table 2). 
Table 2 - Results of the multivariate analyses predicting the presence of depressed mood.

\begin{tabular}{|c|c|c|c|c|c|c|c|c|}
\hline \multirow[b]{3}{*}{ Characteristics } & \multicolumn{6}{|c|}{ Analysis with the entire population, } & \multicolumn{2}{|c|}{$\begin{array}{l}\text { Analysis excluding subjects } \\
\text { with MMSE score }<16 \\
\qquad(\mathrm{~N}=371)\end{array}$} \\
\hline & \multicolumn{2}{|c|}{ GDS cut-off score $\geq 6$} & \multicolumn{2}{|c|}{ GDS cut-off score $\geq 8$} & \multicolumn{2}{|c|}{ GDS cut-off score $\geq 10$} & & \\
\hline & $\begin{array}{l}\text { Adj OR * } \\
(95 \% \text { CI) }\end{array}$ & $p$ & $\begin{array}{c}\text { Adj OR } \\
(95 \% \text { CI) }\end{array}$ & $p$ & $\begin{array}{c}\text { Adj OR } \\
(95 \% \text { CI) }\end{array}$ & $p$ & $\begin{array}{l}\text { Adj OR * } \\
(95 \% \text { CI) }\end{array}$ & $p$ \\
\hline Living alone & $\begin{array}{c}1.8 \\
(1.1-3.0)\end{array}$ & 0.030 & $\begin{array}{c}2.0 \\
(1.0-3.8)\end{array}$ & 0.041 & - & - & $\begin{array}{c}1.8 \\
(1.0-3.1)\end{array}$ & 0.039 \\
\hline Charlson comorbidity & 1.3 & 0.004 & 1.2 & 0.107 & 1.3 & 0.015 & 1.3 & 0.005 \\
\hline index & $(1.1-1.5)$ & & $(1.0-1.4)$ & & $(1.1-1.7)$ & & $(1.1-1.5)$ & \\
\hline Abnormal MMSE & 1.9 & 0.021 & 2.6 & 0.001 & 3.2 & 0.010 & 1.8 & 0.050 \\
\hline score & $(1.1-3.2)$ & & $(1.5-4.8)$ & & $(1.3-7.7)$ & & $(1.0-3.2)$ & \\
\hline
\end{tabular}

* Odds ratio adjusted for age and BADL status in addition to above variables.

\section{Detection rate}

Among the 90 patients with a GDS score of 6 or more, only $15(16.7 \%)$ were identified according to the discharge summary review. Only two of these 15 cases were considered detected because of benzodiazepine prescription. Using higher GDS score cutoffs improved the detection rate only marginally. Cut-off scores of 8 or more, and 10 or more resulted in detection rates of $19.2 \%$ and $22.7 \%$, respectively.

\section{DISCUSSION}

Our results confirm the high prevalence, and the poor recognition rate of depressed mood in older hospitalized persons. The recognition rate found in our study $(16.7 \%)$ is comparable to other studies (2, $26,27)$. Several explanations have been proposed to explain the difficulties in diagnosing depressive problems in this population, such as precedence of acute medical illness, atypical presentation of depression, interaction with multiple comorbidities, or even the assumed normal sadness of elderly persons who are hospitalized. To improve the detection rate, systematic testing with screening instruments such as the GDS have been proposed, but time constraints limit their routine use. Although the GDS has been used as a self-assessment instrument, this strategy seems difficult to implement in an acute care setting.

From this perspective, characteristics associated with a depressed mood in this study could theoretically be used to better target screening efforts. Our results confirm findings of other studies in which both social (living alone) and medical (comorbidity) characteristics have been associated with depressed mood, while age and gender were not $(2,27,29)$. In contrast, our findings differ from those of previous studies in hospitalized elderly which found no relationship between depression and an abnormal MMSE $(2,29)$. This difference may be explained, in part, by differences in population selection and size, setting, and diagnostic criterion used. However, a significant association between depression and cognitive impairment has been described in community-dwelling elderly (28). Complex interactions between depression and cognitive impairment are well documented (42), and thus not surprising.

Despite the positive finding showing an association between depressed mood and several patient characteristics, using these characteristics to enhance detection is unlikely to be successful because of the weakness of the observed statistical associations. Therefore, use of a single pre-screening question, as proposed in the office setting (43), or of the recently tested five-item version of the GDS (40) is probably a promising strategy to enhance recognition of depressed mood in the hospitalized elderly. Further studies are needed to test this approach.

Several limitations of this study need to be mentioned. First, we used a screening instrument (GDS) instead of a structured diagnostic tool as a criterion standard for the diagnosis of depressed mood. To acknowledge this limitation, we used the term depressed mood rather than depression in this study. However, several studies have shown that depressed mood (using similar GDS cut-off) or subsyndromal depression were associated with significant 
functional disability and morbidity $(7-9,18)$. In addition, preliminary results suggest that treatment of subsyndromal depression might benefit patients (44). Second, we used cross-sectional data, and we cannot specify the causal relationship between depressed mood and patient characteristics. Third, the use of the discharge summary to evaluate recognition can also be criticized. Abstracts of the medical records may have given more complete information on the problems addressed during the hospitalization, including depressed mood. However, the discharge summary is the main, and frequently the only written document received by the primary care physician, and should contain all relevant information to be transmitted. The absence of any mention of a depressive problem is likely to result in further delay in its recognition and treatment by the primary care physician. Finally, the very small number of recognized cases made it impossible to achieve further insight into the patient characteristics associated with poor recognition.

Despite these limitations, this study highlights the continuous need for improving the recognition and treatment of depressed mood in hospitalized elderly persons. It must be emphasized that recognition is a necessary but not the only step in the management of depressed elderly patients. Teaching programs for physicians and other professionals that stress the importance of considering and treating depressive problems in elderly patients are equally important to achieve better results (45). The observed associations between depressed mood, functional decline, increased morbidity and mortality suggest that improved recognition and treatment have the potential for improving the overall outcomes and quality of life of these patients.

\section{ACKNOWLEDGEMENTS}

We are grateful to A. Rochat, who collected the data, S. Joray who performed the reliability testing of recognition assessment, N. Corbaz for secretarial assistance, and J.C. Beck for comments on the manuscript. This project was supported by a grant (Fonds de Performance \# 20-1994) from the Public Health Service, Canton of Vaud, Switzerland (to C.J. Büla).

\section{REFERENCES}

1. Gillick M.R., Serrell N.A., Gillick L.S.: Adverse consequences of hospitalization in the elderly. Soc. Sci. Med. 16: 10331038, 1982

2. Koenig H.G., Meador K.G., Cohen H.J., Blazer D.G.: Depression in elderly hospitalized patients with medical illness. Arch. Intern. Med. 148: 1929-1936, 1988.

3. Dunham N.C., Sager M.A.: Functional status, symptoms of depression, and the outcomes of hospitalization in community-dwelling elderly patients. Arch. Fam. Med. 3: 676-681,
1994.

4. Büla C.J., Rubenstein L.Z.: Risks of hospitalization for elderly persons: a clinical overview. Clin. Geriatr. 3: 17-30, 1995.

5. O'Riordan T.G., Hayes J.P., Shelley R., O'Neill D., Walsh B., Coakley D.: The prevalence of depression in acute geriatric medical assessment unit. Int. J. Geriatr. Psychiatry 4: 17-21, 1989.

6. Burn W.K., Davies K.N., McKenzie F.R., Brothwell J.A., Wattis J.P.: The prevalence of psychiatric illness in acute geriatric admissions. Int. J. Geriatr. Psychiatry 8: 171-174, 1993.

7. Roach M.J., Connors A.F., Dawson N.V., Wenger N.S., Wu A.W., Tsevat J., Desbiens N., Covinsky K.E., Schubert D.S.P.: Depressed mood and survival in seriously ill hospitalized adults. Arch. Intern. Med. 158: 397-404, 1998.

8. Covinsky K.E., Fortinsky R.H., Palmer R.M., Kresevic D.M., Landefeld C.S.: Relation between symptoms of depression and health status outcomes in acutely ill hospitalized older persons. Ann. Intern. Med. 126: 417-425, 1997.

9. Covinsky K.E., Kahana E., Chin M.H., Palmer R.M., Fortinsky R.H., Landefeld C.S.: Depressive symptoms and 3-year mortality in older hospitalized medical patients. Ann. Intern. Med. 130: 563-569, 1999

10. Whooley M.A., Browner W.S.: Association between depressive symptoms and mortality in older women. Arch. Intern. Med. 158: 2129-2135, 1998.

11. Ganzini L., Smith D.M., Fenn D.S., Lee M.A.: Depression and mortality in medically ill older adults. J. Am. Geriatr. Soc. 45: 307-312, 1997.

12. Pulska T., Pahkala K., Laippala P., Kivelä S-L.: Follow-up study of longstanding depression as predictor of mortality in elderly people living in the community. BMJ 318: 432-433, 1999.

13. Rovner B.W.: Depression and increased risk of mortality in the nursing home patient. Am. J. Med. 94 (Suppl. 5A): 19S22S, 1993.

14. Wassertheil-Smoller S., Applegate W., Berge K., Chang C.J., Davis B.R., Grimm R., Kostis J., Pressel S., Schron E.: Change in depression as a precursor of cardiovascular events. Arch. Intern. Med. 156: 553-561, 1996.

15. Frasure-Smith N., Lespérance F., Talajic M.: Depression and 18-month prognosis after myocardial infarction. Circulation 91: 999-1005, 1995.

16. Stuck A.E., Walthert J.M., Nikolaus T., Büla C.J., Hohmann C., Beck J.C.: Risk factors for functional status decline in community-living elderly people: a systematic literature review. Soc. Sci. Med. 48: 445-469, 1999.

17. Penninx B.W., Guralnik J.M., Ferrucci L., Simonsick E.M., Deeg D.J.H., Wallace R.B.: Depressive symptoms and physical decline in community-dwelling older persons. JAMA 279: 1720-1726, 1998

18. Lyness J.M., King D.A., Cox C., Yoediono Z., Caine E.D.: The importance of subsyndromal depression in older primary care patients: prevalence and associated functional disability. J. Am. Geriatr. Soc. 47: 647-652, 1999.

19. Callahan C.M., Wolinsky F.D., Stump T.E., Nienaber N.A., Hui S.L., Tierney W.M.: Mortality, symptoms, and functional impairment in late-life depression. J. Gen. Intern. Med. 13: 746-752, 1998.

20. Callahan C.M., Hui S.L., Nienaber N.A., Musick B.S., Tierney W.M.: Longitudinal study of depression and health serv- 
ices use among elderly primary care patients. J. Am. Geriatr. Soc. 42: 833-838, 1994.

21. Unützer J., Patrick D.L., Simon G., Grembowski D., Walker E., Rutter C., Katon W.: Depressive symptoms and the cost of health services in $\mathrm{HMO}$ patients aged 65 years and older. JAMA 277: 1618-1623, 1997.

22. Koenig H.G., Kuchibhatla M.: Use of health services by hospitalized medically ill depressed elderly patients. Am. J. Psychiatry 155: 871-877, 1998.

23. NIH Consensus Development Panel: Diagnosis and treatment of depression in late life. JAMA 268: 1018-1024, 1992.

24. Katz I.R.: Drug treatment of depression in the frail elderly: Discussion of the $\mathrm{NIH}$ consensus development conference on the diagnosis and treatment of depression in late life. Psychopharmacol. Bull. 29: 101-108, 1993.

25. Walker Z., Leek C.A., D'Ath P.J., Katona C.L.E.: Psychiatric morbidity in elderly attenders of an accident and emergency department. Int. J. Geriatr. Psychiatry 10: 951-957, 1995.

26. Rapp S.R., Walsh D.A., Parisi S.A., Wallace C.E.: Detecting depression in elderly medical inpatients. J. Consult. Clin. Psychol. 31: 721-727, 1988.

27. Koenig H.G., Goli V., Shelp F., Kudler H.S., Cohen H.J., Blazer D.G.: Major depression in hospitalized medically ill older men: documentation, management, and outcome. Int J. Geriatr. Psychiatry. 7: 25-34, 1992.

28. Callahan C.M., Hendrie H.C., Dittus R.S., Brater D.C., Hui S.L., Tierney W.M.: Depression in late life: The use of clinical characteristics to focus screening efforts. J. Gerontol. 49: M9-M14, 1994.

29. Koenig H.G., Meador K.G., Shelp F., Goli V., Cohen H.J., Blazer D.G.: Major depressive disorder in hospitalized medically ill patients: An examination of young and elderly male veterans. J. Am. Geriatr. Soc. 39: 881-890, 1991.

30. Koenig H.G., O'Connor C.M., Guarisco S.A., Zabel K.M., Ford S.M.: Depressive disorder in older medical inpatients on general medicine and cardiology services at a university teaching hospital. Am. J. Geriatr. Psychiatry 1: 197-210, 1993.

31. Ramsay R., Wright P., Katz A., Bielawska C., Katona C.: The detection of psychiatric morbidity and its effects on outcome in acute elderly medical admissions. Int. J. Geriatr. Psychiatry 6: 861-866, 1991.
32. Jackson R., Baldwin B.: Detecting depression in elderly medically ill patients: the use of geriatric depression scale compared with medical and nursing observations. Age Ageing 22: 349-353, 1993.

33. Katz S.: Assessing self-maintenance: Activities of daily living, mobility, and instrumental activities of daily living. J. Am. Geriatr. Soc. 31: 721-727, 1983.

34. Lawton M.P., Brody E.M.: Assessment of older people: selfmaintaining and instrumental activities of daily living. Gerontologist 9: 179-186, 1969.

35. Folstein M.F., Folstein S.E., McHugh P.R.: Mini Mental State. A practical method for grading the cognitive state of patients for the clinician. J. Psychiatr. Res. 12: 189-198, 1975.

36. Sheikh J.I., Yesavage J.A.: Geriatric Depression scale (GDS): recent evidence and development of a shorter version. Clin. Gerontol. 5: 165-173, 1986.

37. Bourque P., Blanchard L.: Etude psychométrique de l'échelle de dépression gériatrique. Can. J. Aging 9: 348-355, 1990.

38. Charlson M.E., Pompei P., Ales K.L., MacKenzie C.R.: A new method of classifying prognostic comorbidity in longitudinal studies: Development and validation. J. Chron. Dis. 40: 373-383, 1987.

39. Gerety M.B., Williams J.W.Jr., Mulrow C.D., Cornell J.E., Kadri A.A., Rosenberg J., Chiodo L.K., Long M.: Performance of case-finding tools for depression in the nursing home: influence of clinical and functional characteristics and selection of optimal threshold scores. J. Am. Geriatr. Soc. 42: 1103-1109, 1994.

40. Hoyl M.T., Alessi C.A., Harker J.O., Josephson K.R., Pietruszka F.M., Koelfgen M., Mervis J.R., Fitten L.J., Rubenstein L.Z.: Development and testing of a five-item version of the Geriatric Depression Scale. J. Am. Geriatr. Soc. 47: 873-878, 1999.

41. Rickels K., Feingnher J.P., Smith W.T.: Alprazolam, amitriptyline, doxepin, and placebo in the treatment of depression. Arch. Gen. Psychiatry 42: 134-141, 1985.

42. Lamberty G.J., Bieliauskas L.A.: Distinguishing between depression and dementia in the elderly: a review of neuropsychological findings. Arch. Clin. Neuropsychol. 8: 149-170, 1993.

43. Mahoney J., Drinka T.J.K., Abler R., Gunter-Hunt G., Matthews C., Gravenstein S., Carnes M.: Screening for depression: single question versus GDS. J. Am. Geriatr. Soc. 42: 1006-1008, 1994

44. Oxman T., Barrett J., Williams J., Frank E., Katon W.: The treatment effectiveness project. Gerontologist 39: 373,1999 (Abstract).

45. Butler R., Collins E., Katona C., Orrell M.: Does teaching programme improve general practitioners' management of depression in the elderly. J. Affect. Disord. 46: 303-308, 1997. 